\title{
Membangun Keunggulan Kompetitif Melalui Orientasi Pasar, Kreativitas Produk dan Inovasi Produk Pada IKM Kerajinan Kabupaten Bantul Yogyakarta
}

\author{
Andika*1, Muinah Fadhilah², Ambar Lukitaningsih ${ }^{3}$ \\ Universitas Sarjanawiyata Tamansiswa \\ *Correspondence email: andikasholeh123@gmail.com, muinahfadhilah@ustjogja.ac.id
}

\begin{abstract}
The purpose of this study was to address the gaps in the results of previous studies regarding the effect of market orientation and product creativity on competitive advantage by adding an intervening variable, namely product innovation. This research is located in Bantul Regency, involving 100 respondents who act as owners or managers of IKM Crafts. The sampling technique used was the method Consecutive Sampling. The model analysis technique and hypothesis testing used by researchers is the Partial Least Square (PLS) analysis with SmartPLS 3.3.3 software, while the mediation analysis uses the Sobel test. The results obtained in this study indicate that market orientation has a significant effect on product innovation and competitive advantage; Product creativity has a significant effect on product innovation but not significant on competitive advantage. The results of the single-test analysis show that product innovation is able to significantly mediate the effect of product creativity on competitive advantage but is unable to act as a mediator on the effect of market orientation on competitive advantage. The limitation of this research is that the data collected is limited to IKM Crafts in Bantul Regency. Practical Implications - Craft SMIs should consider the application of product innovation through market orientation and product creativity to build competitive advantage. When product innovation through market orientation and product creativity is implemented properly, competitive advantage can be achieved.
\end{abstract}

Keywords: Competitive Advantage; IKM Handicraf; Market Orientation; Product Creativity; Product Innovation.

\section{Pendahuluan}

Pengembangan ekonomi nasional seyogianya menjadikan sektor ekonomi kreatif sebagai salah satu prioritas, karena ekonomi kreatif menjadi tulang punggung sistem ekonomi kerakyatan yang mampu memberikan peran yang jauh lebih besar jika dikembangkan dengan baik, seperti dapat memperluas dan meratakan kesempatan usaha, menyerap tenaga kerja, hingga mempercepat pertumbuhan ekonomi daerah maupun nasional (Yuniarti et al., 2018; dan Ayandibu and Houghton, 2017). Ekonomi kreatif merupakan isu yang banyak dikaji oleh cendikiawan belakangan ini, seperti Petry et al., 2020; Fazlagic and Skikiewicz, 2019; dan Symons and Hurley, 2018. Sebab, salah satu sektor ekonomi global yang tumbuh paling cepat adalah ekonomi kreatif (Streimikiene and Kacerauskas, 2020).

Salah satu Kabupaten/Kota di Indonesia yang memiliki potensi yang besar dalam pengembangan ekonomi kreatif adalah Kabupaten Bantul, hal tersebut didasari oleh ditetapkannya Kabupaten Bantul sebagai salah satu dari 15 kabupaten/kota kreatif di Indonesia (Fitri, 2018). Salah satu subsektor ekonomi kreatif yang paling terkenal di Kabupaten Bantul adalah Industri Kerajinan (yang selanjutnya disebut IKM kerajinan), dimana sebanyak 80\% produk kerajinan di Daerah Istimewa Yogyakarta berasal dari Kabupaten Bantul, mulai dari barang perhiasan, tatah sungging, pelepah pisang, asesoris keris, kerajinan kayu, batik kayu dan lain sejenisnya (LKj Pemerintah Kab. Bantul, 2019). Pemberdayaan IKM Kerajinan di tengah dampak globalisasi dan persaingan yang semakin ketat membuat IKM kerajinan harus mampu menghadapi ancaman global bila ingin maju dan berkembang. Sumber daya manusia yang mempunyai kreativitas dan inovasi yang tinggi sangat dibutuhkan dalam pemberdayaan IKM kerajinan guna mewujudkan keunggulan kompetitif. Timbulnya inovasi dan kreativitas di tengah masyarakat memiliki misi penting dalam meningkatkan perekonomian suatu wilayah (Rifa'i, Sasongko and Indrihastuti, 2019).

Strategi bersaing merupakan taktik yang dapat digunakan para pelaku IKM kerajinan dalam menghadapi persaingan (Suhaeni, 2018). Strategi pengembangan yang berorientasi pasar dan kreativitas adalah salah satu bagian primer yang mendorong terciptanya keunggulan kompetitif. Terciptanya keunggulan kompetitif yang berkesinambungan bagi IKM kerajinan sangat dibutuhkan agar mampu bersaing di pasar regional hingga pasar global (Sutapa, et al., 2017). Agar berhasil memasuki pasar regional dan global, pelaku IKM kerajinan harus mampu merespon segera kebutuhan pelanggan dan kondisi pasar baru. IKM kerajinan secara terus menerus wajib mencari jalan keluar kreatif serta melakukan pengembangan dan penyempurnaan secara berkesinambungan dalam memproduksi barang yang sesuai dengan keinginan pelanggan. Orientasi pasar merupakan hal yang fundamental untuk para pelaku IKM kerajinan, karena tidak semua pelaku IKM kerajinan berorientasi pada pasar (Anjaningrum and Sidi, 2018). Penelitian Zaman Khan et al. (2016) membuktikan bahwa orientasi pasar dapat meningkatkan keunggulan kompetitif, yaitu menawarkan produk secara lebih efektif dengan memahami kebutuhan dan keinginan pelanggan. Akan tetapi penelitian Zainul et al. (2016) tidak mampu membuktikan bahwa orientasi pasar dapat 
meningkatkan keunggulan kompetitif. Namun, jika hanya memiliki orientasi pasar tentu belum cukup jika tidak dibarengi dengan kreativitas sebagai kunci utama terciptanya produk kreatif yang bisa meningkatkan keunggulan kompetitif. Noviani (2020) menyatakan bahwa kreativitas produk melibatkan kemampuan guna mengoptimalkan dan mengintegrasikan ide baru dari ide-ide yang sudah ada dari pelanggan sehingga mampu menciptakan kreativitas produk yang dapat berdampak pada keunggulan kompetitif.

Anjaningrum and Sidi (2018) menganalisis pengaruh kreativitas produk terhadap keunggulan kompetitif dan pengaruh keunggulan kompetitif terhadap performa industri Kreatif. Hasil penelitiannya mengungkapkan bahwa kreativitas produk memberi pengaruh pada keunggulan kompetitif secara positif dan signifikan. Penelitian tersebut senada dengan penelitian Kurniasari and Utama (2018); Ruzikna (2018); dan Bashor and Purnama (2017). Namun, penelitian lain menunjukkan bahwa kretivitas produk berpengaruh positif tetapi tidak signifikan terhadap keunggulan kompetitif seperti penelitian Sutapa, Mulyana and Wasitowati (2017) dan Lee and Rodríguez-Pose (2014). Berdasarkan penelitian tersebut, menunjukkan bahwa masih adanya kesenjangan hasil penelitian tentang pengaruh orientasi pasar dan kreativitas produk terhadap keunggulan kompetitif. Beberapa penelitian mengungkapkan bahwa orientasi pasar dan kreativitas produk memiliki pengaruh positif dan signifikan terhadap keunggulan kompetitif (Anjaningrum and Sidi, 2018; Kurniasari and Utama, 2018; Ruzikna, 2018; Bashor and Purnama, 2017; dan Zaman Khan et al., 2016), sedangkan beberapa penelitian lainnya menyatakan bahwa orientasi pasar dan kreativitas produk tidak memiliki pengaruh terhadap keunggulan kompetitif (Sutapa et al., 2017; Zainul et al., 2016; dan Lee and Rodríguez-Pose, 2014). Oleh karena itu untuk mengatasi kesenjangan hasil penelitian tersebut, pada penelitian ini peneliti menambahkan variabel mediasi, yaitu inovasi produk. Karena inovasi produk diyakini sebagai mediator potensial dari hubungan orientasi pasar dan kreativitas produk terhadap keunggulan kompetitif.

\section{Kajian Teori dan Hipotesis}

Keunggulan Kompetitif.

Pandangan berbasis sumber daya (Resource-based View/RBV) menarik perhatian ke lingkungan internal perusahaan sebagai mesin keunggulan kompetitif dan menekankan sumber daya yang telah dikembangkan perusahaan untuk bersaing di lingkungan (Wang, 2014). RBV didasarkan pada keyakinan bahwa keunggulan kompetitif tidak bergantung pada karakteristik pasar dan industri, melainkan pada sumber kekuatan internal yang diproduksi oleh perusahaan (Kumlu, 2014). RBV memungkinkan perusahaan untuk mengidentifikasi sumber kekuatan (berwujud dan tidak berwujud) dan menentukan kemampuannya guna memperoleh keunggulan kompetitif atas pesaingnya (Muharam, 2017). Menurut Assensoh-Kodua (2019) pemahaman lengkap tentang sumber keunggulan kompetitif perusahaan memerlukan analisis kekuatan internalnya (misalnya segmentasi), kelemahan (kurangnya staf terampil, pengetahuan dan banyak lainnya), yang tidak sejalan dengan RBV. Esensi utama dari resource-based View adalah sumber kekuatan yang mampu menciptakan keunggulan kompetitif, yaitu sesuatu yang unik, berharga, sulit dilacak dan tidak memiliki alternatif. Sebagaimana Aziz and Samad (2016) juga mengatakan bahwa ketika perusahaan mampu menawarkan produk yang berkualitas dengan harga yang lebih terjangkau dari para pesaingnya serta mampu memberikan pelayanan yang terbaik maka perusahaan tersebut dapat dikatakan memiliki keunggulan kompetitif. Singkatnya, ide sumber daya terletak di pusat teori ini yang memandang kebutuhan akan sumber daya yang memiliki karakteristik unik dan tahan lama dapat memungkinkan organisasi mencapai keunggulan kompetitif.

Menurut Wang (2014) Keunggulan kompetitif diperoleh pada waktu perusahaan mengembangkan atau memperoleh serangkaian sifat (atau melakukan tindakan) yang memungkinkannya mengungguli pesaingnya. Dipertegas oleh Anwar et al. (2018) bahwa keunggulan kompetitif merupakan keunggulan strategis perusahaan dibandingkan dengan pesaing di industri sehingga dapat berkinerja lebih baik. Berdasarkan literatur yang disebutkan di atas, dapat disimpulkan bahwa keunggulan kompetitif dengan menerapkan pandangan berbasis sumber kekuatan perusahaan (resource based view/RBV) merupakan kemampuan perusahaan dalam memaksimalkan sumber kekuatan internal yang unggul di perusahaan dengan cara mengidentifikasi sumber kekuatan (berwujud dan tidak berwujud) yang dimiliki dan menentukan kemampuannya sehingga unggul dibandingkan dengan perusahaan lainnya. Perusahaan memiliki keunggulan kompetitif jika mampu menghantarkan produk berkualitas tinggi dengan harga yang terjangkau serta mampu menghantarkan produk atau jasa yang unik dibandingkan dengan perusahaan lain.

\section{Orientasi Pasar}

Orientasi pasar merupakan fenomena mendasar dalam pengukuran operasi pemasaran selama dua dekade terakhir (Ladipo et al., 2016; Sombultawee and Boon-itt, 2018). Orientasi pasar mencerminkan budaya perusahaan dengan berusaha menciptakan nilai pelanggan yang unggul dan menggali tren pasar untuk memberikan manfaat yang lebih besar bagi pelanggan (Mamun et al., 2018). Orientasi pasar menetapkan beberapa norma mengenai pengumpulan informasi dan daya tanggap organisasi yang luas terhadap informasi yang berkaitan dengan pelanggan (potensial dan aktual) sehingga perusahaan dapat mendahului pesaing dalam analisis pasar dan bereaksi terhadap kebutuhannya (Ghorbani et al., 2014). Dampak perusahaan yang berorientasi pasar ialah memiliki keunggulan kompetitif yang baik 
dalam membantu memahami preferensi pelanggan dan strategi pesaing serta perubahan skenario pasar secara keseluruhan sehingga perusahaan dapat membedakan, merancang, memposisikan dan meningkatkan produk serta jasanya dengan cara menciptakan nilai bagi pelanggan (Zaman Khan et al., 2016). Ditinjau dari perspektif budaya, orientasi pasar merupakan kemampuan untuk mengelola nilai-nilai budaya yang abstrak menjadi perilaku berwujud yang mencerminkan nilai-nilai bersama organisasi yang menempatkan nilai pelanggan sebagai tujuan utama (Raju et al., 2011); dari perspektif perilaku, orientasi pasar merupakan kemauan dan kemampuan organisasi untuk merancang proses pengumpulan informasi pasar, menyebarluaskan dan memantau tingkat komitmen organisasi untuk secara rutin melayani kebutuhan pelanggan (Roach et al., 2014); dari perspektif teori resource-based view (RBV), orientasi pasar merupakan budaya dan kapabilitas organisasi yang mampu memberikan keunggulan kompetitif (Roach et al., 2014); dan secara umum menurut Na, Kang and Jeong (2019) orientasi pasar merupakan kecenderungan kegiatan organisasi untuk merespon permintaan pasar lebih baik dari pesaing dan memprediksi perubahan pasar dengan baik untuk membangun keunggulan kompetitif yang berkelanjutan dan keuntungan yang tinggi.

Berdasarkan beberapa literatur dapat disimpulkan bahwa orientasi pasar merupakan sebuah budaya perusahaan yang menempatkan pasar sebagai kunci kelangsungan hidup perusahaan tersebut. Sebab itu, untuk menjaga eksistensi perusahaan di tengah dampak persaingan yang semakin ketat, pasar harus didesain secara efektif dan efisien, dengan cara mengumpulkan informasi dan menggali tren pasar serta merancang dan menyesuaikan produk, layanan dan proses perusahaan agar sesuai dengan selera dan kebutuhan pelanggan sehingga dapat membangun keunggulan kompetitif dan menghasilkan profit yang tinggi.

\section{Kreativitas Produk}

Banyak akademisi setuju bahwa istilah kreatif dikaitkan dengan kebaruan dan kegunaan. Dimana suatu produk wajib mempunyai dua ciri ini agar memenuhi syarat sebagai kreatif. Sebab, jika suatu produk itu asli dan unik tetapi tidak bermanfaat bagi masyarakat atau sesuatu yang bermanfaat tetapi tidak inovatif maka tidak dapat dikatakan kreatif (Piffer, 2012). Kelangsungan hidup jangka panjang perusahaan di pasar kompetitif bergantung pada seberapa baik perusahaan mewujudkan ide-ide kreatifnya dalam produk yang mampu memenuhi kebutuhan dan harapan pelanggan yang terus berubah (Im et al., 2013). Tremblay (2011) mengemukakan bahwa kreativitas berkaitan dengan kemampuan individu atau kelompok untuk menciptakan, menemukan atau membayangkan sesuatu yang baru. Diperjelas oleh Romli (2019) bahwa kreativitas berkaitan dengan kemampuan menciptakan ide atau gagasan. Kreativitas masih dalam bentuk ide, belum dalam bentuk produk. Namun jika kreativitas diwujudkan dalam bentuk produk, maka produk tersebut dapat disebut sebagai hasil inovasi. Menurut Ernawati and Kurniawati (2020) kreativitas produk dapat diterapkan dengan menciptakan ide baru atau ide yang telah ada kemudian diperbaharui serta dapat berasal dari sumber lain sehingga kreativitas produk bisa dijadikan stategi untuk mempertahankan pasar serta mempertahankan keunggulan kompetitif yang dimiliki perusahaan. Hal sama juga diutarakan oleh Bashor and Purnama (2017) bahwa kreativitas produk adalah kemampuan mengembangkan ide-ide baru dan menemukan caracara baru untuk memecahkan masalah dalam menghadapi peluang bisnis. Kreativitas menitikberatkan pada tiga kompetensi, yaitu kompetensi menggabungkan, kompetensi memecahkan masalah dan kompetensi kreatif secara operasional. Sedangkan menurut Hadiyati (2011) kreativitas produk merupakan ide pada suatu produk atau proses yang bermanfaat, benar, tepat dan bermutu terhadap suatu fungsi yang lebih bersifat heuristic yaitu sesuatu yang merupakan norma, pedoman atau panduan tidak lengkap yang dapat membimbing kita untuk memahami, mempelajari atau menciptakan sesuatu yang baru. Beberapa literatur yang disebutkan di atas, dapat disimpulkan bahwa kreativitas produk adalah kemampuan untuk menciptakan dan mengembangkan ide produk yang unik, orisinal dan berbeda dari produk pesaing dengan menambahkan beberapa fitur baru untuk memenuhi kebutuhan dan harapan konsumen. Hal ini berarti perusahaan harus menemukan ide baru yang akan diterapkan untuk mewujudkan keunggulan kompetitif bagi perusahaan (Reguia, 2014).

\section{Inovasi Produk.}

Odumeru (2013) mengemukakan bahwa Inovasi adalah strategi yang diadopsi secara luas oleh sebagian besar organisasi dalam perekonomian saat ini. Menurut Zizlavsky (2011), schumpeter pertama kali menggunakan istilah "inovasi" pada awal abad ke-20. Ide dan penelitiannya dikembangkan oleh sejumlah peneliti lain. Schumpeter mendefinisikan inovasi sebagai produk, proses dan perubahan organisasi yang tidak selalu berasal dari penemuan ilmiah baru, tetapi mungkin muncul dari campuran teknologi yang ada dan aplikasinya dalam konteks baru (Zizlavsky, 2011). Dipertelas oleh Bruno et al. (2011) bahwa inovasi adalah proses mengubah ide baru menjadi produk atau prosedur baru yang meningkatkan produktivitas. Menurut Carboni and Russu (2018) inovasi produk adalah produk atau layanan baru yang dihadirkan ke pasar untuk melayani kebutuhan pasar atau dikembangkan untuk memenuhi kebutuhan pelanggan eksternal. Inovasi dianggap sebagai salah satu fitur sukses dalam ekonomi perusahaan yaitu sebagai elemen dasar untuk mencapai kepuasan pelanggan dan untuk mewujudkan keinginannya. Hal yang sama juga diutarakan oleh D. Chang and Chen (2014) bahwa inovasi produk adalah penciptaan dan pengenalan produk baru atau 
lebih baik dari produk sebelumnya yang memberikan pendekatan untuk membantu perusahaan dalam mencapai perbaikan dan meningkatkan daya saing. Sedangkan menurut Atalay et al. (2013) Inovasi produk merupakan pengenalan dan kelanjutan produk baru yang berbeda dengan produk sebelumnya, serta perbaikan kelemahan produk yang sudah ada dengan mengutamakan kualitas. Berdasarkan beberapa literatur yang telah disebutkan di atas, dapat disimpulkan bahwa inovasi produk adalah proses mengubah ide-ide baru menjadi penciptaan dan pengenalan produk baru dari perusahaan yang sesuai kebutuhan pasar serta mengembangkan atau menyempurnakan produk-produk yang sudah ada agar sesuai dengan keinginan pelanggan saat ini. Di tengah persaingan yang kompetitif, perusahaan dituntut untuk mampu meningkatkan inovasi produk guna mencapai keunggunan kompetitif dan memenangkan pasar baru.

\section{Hubungan Orientasi Pasar dan Inovasi Produk.}

Menurut Kumar et al. (2011) orientasi pasar merupakan kemampuan dan budaya yang menjadi prinsip perusahaan. Tujuan utama dari orientasi pasar yaitu mengantarkan nilai atau value yang unggul untuk pelanggan yang didasarkan pada pengetahuan yang berasal dari analisa pelanggan dan pesaing, dimana pengetahuan yang telah diperoleh tersebut kemudian disebarkan ke seluruh elemen perusahaan. Dari pengetahuan tersebut, perusahaan harus dapat memenuhi kebutuhan dan keinginan pelanggan melalui inovasi produk, baik berupa menciptakan produk baru maupun mengembangkan produk yang sudah ada, sehingga dapat memberikan nilai unggul kepada pelanggannya secara berkelanjutan dan dapat menjadi modal utama perusahaan untuk memenangkan persaingan (Putra and Rahanatha, 2017). Sehingga dapat dikatakan bahwa orientasi pasar memiliki pengaruh atas terciptanya berbagai produk dari hasil proses inovasi. Hal ini sejalan dengan temuan penelitian Sukaryawan (2013); Fadhilah and Andriyansah (2017); Wilches et al. (2018); Na, Kang and Jeong (2019); Sukartini et al. (2019); Shaher and Ali (2020) dan Aydin (2020) yang menunjukkan bahwa orientasi pasar berpengaruh positif dan signifikan terhadap terciptanya inovasi. Berdasarkan uraian di atas, maka hipotesis dalam penelitian ini dapat dirumuskan sebagai berikut:

$\mathrm{H}_{1}$ : Orientasi pasar berpengaruh signifikan terhadap inovasi produk

\section{Hubungan Orientasi Pasar dan Keunggulan Kompetitif.}

Orientasi pasar mencerminkan budaya perusahaan dengan berusaha menciptakan nilai pelanggan yang unggul dan menggali tren pasar untuk memberikan manfaat yang lebih besar bagi pelanggan (Mamun et al., 2018). Orientasi pasar menetapkan beberapa norma mengenai pengumpulan informasi dan daya tanggap organisasi yang luas terhadap informasi yang berkaitan dengan pelanggan (potensial dan aktual) sehingga perusahaan dapat mendahului pesaing dalam analisis pasar dan bereaksi terhadap kebutuhannya (Ghorbani et al., 2014). Dampak perusahaan yang berorientasi pasar yaitu memiliki keunggulan kompetitif yang baik dalam membantu memahami preferensi pelanggan, strategi pesaing serta perubahan dalam skenario pasar secara keseluruhan sehingga perusahaan dapat membedakan, merancang, memposisikan dan meningkatkan produk dan layanannya dengan menciptakan nilai bagi pelanggan (Zaman Khan et al., 2016). Hal tersebut sejalan dengan temuan Talaja et al. (2017); Udriyah et al. (2019); Pratono et al. (2019); Kumbara and Afuan (2019) dan Puspaningrum (2020) yang mengungkapkan bahwa orientasi pasar berpengaruh terhadap terciptanya keunggulan Kompetitif. Berdasarkan uraian di atas, maka hipotesis dalam penelitian ini dapat dirumuskan sebagai berikut:

$\mathrm{H}_{2}$ : Orientasi pasar berpengaruh signifikan terhadap keunggulan Kompetitif

\section{Hubungan Kreativitas Produk dan Inovasi Produk.}

Marinho et al. (2016) mengungkapkan bahwa inovasi dan kreativitas memiliki hubungan yang saling melengkapi dan saling bergantung. Kreativitas sebagai kemampuan menciptakan atau mengembangakan ide baru atau ide yang telah ada kemudian diperbaharui. Sedangkan inovasi menindaklanjuti ide baru atau ide yang telah diperbaharui menjadi sebuah produk nyata yang sesuai dengan keinginan atau kebutuhan pelanggan. Sehingga memiliki ide yang kreatif saja tentu dirasa belum cukup jika tidak diwujudkan menjadi sebuah produk nyata yang mampu menjaga eksistensi perusahaan ditengah persaingan yang kompetitif. Sebagaimana yang dikatakan oleh Im et al. (2013) bahwa kelangsungan hidup jangka panjang perusahaan di pasar kompetitif bergantung pada seberapa baik perusahaan mewujudkan ide-ide kreatifnya dalam sebuah produk yang mampu memenuhi perubahan kebutuhan dan harapan pelanggan. Hal Ini mengisyaratkan bahwa kreativitas berpengaruh terhadap lahirnya inovasi produk. Sebagaimana dikemukakan Lee and Rodríguez-Pose (2014) bahwa kreatifitas merupakan pendorong inovasi yang mendasar. Hal ini diperkuat dengan hasil penelitian dari Sarooghi et al. (2015); Valaei et al. (2017); Anjaningrum and Sidi (2018); Ogbeibu et al. (2019) dan Ferreira et al. (2020) yang menunjukkan bahwa kreativitas produk berpengaruh terhadap lahirnya berbagai produk-produk dari hasil inovasi produk. Berdasarkan uraian di atas, maka hipotesis dalam penelitian ini dapat dirumuskan sebagai berikut:

$\mathrm{H}_{3}$ : Kreativitas produk berpengaruh signifikan terhadap inovasi produk 


\section{Hubungan Kreativitas Produk terhadap Keunggulan Kompetitif.}

Tremblay (2011) mengemukakan bahwa kreativitas berkaitan dengan kemampuan individu atau kelompok untuk menciptakan, menemukan, atau membayangkan sesuatu yang baru. Kreativitas produk dapat diterapkan dengan menciptakan ide baru atau ide yang telah ada kemudian diperbaharui serta dapat berasal dari sumber lain sehingga kreativitas produk bisa dijadikan stategi untuk mempertahankan pasar serta mempertahankan keunggulan kompetitif yang dimiliki perusahaan (Ernawati and Kurniawati, 2020). Hal ini berarti bahwa eksistensi keunggulan kompetitif yang dimiliki perusahaan dipengaruhi oleh kreativitas produk. Hal ini senada dengan hasil penelitian Kosar et al. (2017); Bashor and Purnama (2017); Zameer et al. (2019); Noviani (2020) dan Yusuf et al. (2020) yang mengungkapkan bahwa kreativitas berpengaruh signifikan terhadap keunggulan kompetitif. Berdasarkan uraian di atas, maka hipotesis dalam penelitian ini dapat dirumuskan sebagai berikut:

$\mathrm{H}_{4}$ : Kreativitas produk berpengaruh signifikan terhadap keunggulan kompetitif

\section{Hubungan Inovasi Produk dan Keunggulan Kompetitif.}

Tiap perusahaan dituntut untuk senantiasa memperhatikan dan memahami apa yang terjadi di pasar dan apa yang diharapkan konsumen, serta perubahan untuk berkompetisi dengan kompetitor. Di tengah lingkungan yang amat kompetitif tersebut, penting bagi perusahaan untuk membedakan dirinya dari pesaing lain di pasar dan mencapai keunggulan kompetitif. Dalam hal ini, inovasi produk dapat memainkan peran penting untuk mencapai posisi tersebut dan ini juga dianggap sebagai faktor kunci dibalik kesuksesan berbagai bisnis (Salerno et al., 2015). Sebagaimana dikatakan oleh Aksoy (2017) bahwa Inovasi merupakan salah satu strategi yang memungkinkan bagi perusahaan untuk menghadapi persaingan bisnis, dimana inovasi dapat menjadi pembeda di tengah persaingan bisnis dan berdampak pada keunggulan kompetitif dan menciptakan pasar baru. Hal tersebut sejalan dengan hasil penelitian dari Aziz and Samad (2016); Tarus et al. (2017); Nuryakin (2018); Kariuki (2017) dan Aktharsha and Prabhu (2019) yang menunjukkan bahwa inovasi produk berpengaruh signifikan terhadap tercapainya keunggulan kompetitif perusahaan. Berdasarkan uraian di atas, maka hipotesis dalam penelitian ini dapat dirumuskan sebagai berikut: $\mathrm{H}_{5}$ : Inovasi Produk berpengaruh signifikan terhadap keunggulan kompetitif

\section{Peran Inovasi Produk dalam memediasi pengaruh Orientasi Pasar terhadap Keunggulan Kompetitif.}

Lingkungan persaingan di sektor industri saat ini sangat kompleks, sehingga setiap perusahaan harus mampu memahami dan menginterpretasikan apa yang terjadi di pasar dan apa yang menjadi hasrat konsumen, serta perubahannya agar dapat bersaing dengan kompetitor. Hal inilah yang disebut orientasi pasar. Menurut Kumar et al. (2011) tujuan utama dari orientasi pasar yaitu mengantarkan nilai atau value yang unggul untuk pelanggan yang didasarkan pada pengetahuan yang berasal dari analisa pelanggan dan pesaing, dimana pengetahuan yang telah diperoleh tersebut kemudian disebarkan ke seluruh elemen perusahaan. Dari pengetahuan tersebut, perusahaan harus dapat memenuhi kebutuhan dan harapan konsumen melalui inovasi produk yang disesuaikan dengan kebutuhan pasar, baik berupa menciptakan produk baru ataupun mengoptimalkan produk yang telah ada. Sebagaimana dikatakan oleh Aksoy (2017) bahwa Inovasi ialah salah satu strategi yang memungkinkan perusahaan dalam menghadapi persaingan industri, karena inovasi dapat menjadi faktor pembeda di tengah persaingan bisnis dan berdampak pada keunggulan kompetitif serta penciptaan pasar baru. Hal demikian berarti bahwa inovasi produk bisa memediasi hubungan orientasi pasar kepada keunggulan kompetitif. Berdasarkan uraian di atas, maka hipotesis dalam penelitian ini dapat dirumuskan sebagai berikut:

$\mathrm{H}_{6}$ : Inovasi Produk mampu memediasi orientasi pasar terhadap keunggulan kompetitif secara signifikan

\section{Peran inovasi produk dalam memediasi pengaruh kreativitas produk terhadap keunggulan kompetitif}

Menurut Lee and Rodríguez-Pose (2014) bahwa kreatifitas merupakan pendorong inovasi yang mendasar. Dipertegas oleh Romli (2019) bahwa kreativitas berkaitan dengan kemampuan menciptakan ide atau gagasan. Kreativitas masih dalam bentuk ide, belum dalam bentuk produk. Namun jika kreativitas diwujudkan dalam bentuk produk, maka produk tersebut bisa disebut sebagai hasil inovasi. Hal tersebut berarti bahwa kreativitas sebagai kemampuan menciptakan atau mengembangakan ide baru atau ide yang telah ada kemudian diperbaharui. Sedangkan inovasi menindaklanjuti ide baru atau ide yang telah diperbaharui menjadi sebuah produk nyata yang sesuai dengan keinginan atau kebutuhan pelanggan. Sehingga memiliki ide yang kreatif saja tentu dirasa belum cukup jika tidak diwujudkan menjadi sebuah produk nyata melalui inovasi produk yang mampu menciptakan keunggulan kompetitif. Sebagaimana diungkapkan oleh Salerno et al. (2015) bahwa inovasi produk dapat memainkan peran penting untuk mencapai posisi keunggulan kompetitif dan inovasi produk juga dianggap sebagai faktor kunci di balik kesuksesan berbagai bisnis. Hal demikian berarti bahwa inovasi produk bisa memediasi hubungan kreativitas produk terhadap keunggulan kompetitif. Berdasarkan uraian di atas, maka hipotesis dalam penelitian ini dapat dirumuskan sebagai berikut:

$\mathrm{H}_{7}$ : Inovasi Produk mampu memediasi orientasi pasar terhadap keunggulan kompetitif secara signifikan 
Andika et al., Membangun Keunggulan Kompetitif Melalui Orientasi Pasar, Kreativitas Produk dan Inovasi Produk Pada IKM Kerajinan Kabupaten Bantul Yogyakarta

\section{Hasil}

Tabel 1

Validitas Konvergen (Outer Loading)

\begin{tabular}{|c|c|c|c|c|c|}
\hline \multirow{2}{*}{ Indikator } & \multicolumn{4}{|c|}{ Variabel Laten } & \multirow{2}{*}{ Status } \\
\hline & Orientasi Pasar $(\mathbf{X} \mathbf{I})$ & Kreativitas Produk (X2) & Inovasi Produk(Y1) & Keunggulan Kompetitif (Y2) & \\
\hline $\mathrm{OP} 2$ & 0.620 & & & & Valid \\
\hline OPS3 & 0.732 & & & & Valid \\
\hline KF1 & 0.806 & & & & Valid \\
\hline KF2 & 0.708 & & & & Valid \\
\hline $\mathrm{KF} 3$ & 0.798 & & & & Valid \\
\hline $\mathrm{KB} 2$ & & 0.710 & & & Valid \\
\hline KB3 & & 0.653 & & & Valid \\
\hline RS1 & & 0.782 & & & Valid \\
\hline RS2 & & 0.802 & & & Valid \\
\hline GY1 & & 0.729 & & & Valid \\
\hline GY2 & & 0.733 & & & Valid \\
\hline PB2 & & & 0.715 & & Valid \\
\hline TLP2 & & & 0.686 & & Valid \\
\hline RPP1 & & & 0.757 & & Valid \\
\hline KB1 & & & & 0.736 & Valid \\
\hline $\mathrm{KB} 2$ & & & & 0.790 & Valid \\
\hline KB3 & & & & 0.721 & Valid \\
\hline
\end{tabular}

Sumber : Data Olahan

Untuk melihat validitas masing-masing Indikator yang membentuk suatu konstruk dapat dilihat dari nilai validitas konvergen dan validitas diskriminan. Validitas konvergen diukur dari korelasi antara skor indikator dengan konstruknya. Indikator konvergen dikatakan valid jika memiliki nilai loading factor lebih dari 0,50. Jika ada indikator yang tidak memenuhi persyaratan tersebut maka harus dihilangkan. Nilai loading factor $>0,70$ sangat baik, tetapi $>$ 0,60 sudah dianggap cukup (Hair et al., 2017). Tabel 1 menunjukkan bahwa semua konstruk orientasi pasar, kreativitas produk, inovasi produk dan keunggulan kompetitif valid, karena semua indikator memiliki loading factor lebih besar dari 0,50. Validitas diskriminan diukur dari cross loading antara indikator dengan konstruknya. Indikator dinyatakan valid jika hubungan indikator dengan konstruknya lebih tinggi daripada hubungannya dengan konstruk yang lain, atau dapat juga diukur melalui nilai AVE harus diatas 0,50 (Hair et al., 2017). Tabel 2 menunjukkan bahwa nilai AVE untuk semua konstruk dalam orientasi pasar, kreativitas produk, inovasi produk dan keunggulan kompetitif lebih besar dari 0,50.

Tabel 2

Hasil Uji Validitas Diskriminan (AVE)

\begin{tabular}{|l|c|c|c|}
\hline \multicolumn{1}{|c|}{ Variabel } & Kriteria & AVE & Kesimpulan \\
\hline Orientasi Pasar & \multirow{2}{*}{$>0.50$} & 0.542 & Valid \\
\cline { 1 - 3 } Kreativitas Produk & & 0.542 & Valid \\
\cline { 1 - 3 } Inovasi Produk & & 0.518 & Valid \\
\cline { 1 - 3 } Keuanggulan kompetitif & & 0.562 & Valid \\
\hline
\end{tabular}

Sumber : Data Olahan

Reliabilitas komposit merupakan ukuran konsistensi internal dari indikator-indikator sebuah variabel bentukan yang menunjukkan derajat dalam variabel yang dibentuk. Konstruk dinyatakan memiliki reliabel yang baik apabila reliabilitas komposit memiliki nilai > 0,70 (Hair et al., 2017). Tabel 3 menunjukkan bahwa semua konstruk orientasi pasar, kreativitas produk, inovasi produk dan keunggulan kompetitif dapat diandalkan karena nilai reliabilitas komposit lebih besar dari 0.70 .

Tabel 3

Hasil Uji Reliabilitas Komposit

\begin{tabular}{|l|c|c|c|}
\hline \multicolumn{1}{|c|}{ Variabel } & Kriteria & Reliabilitas Komposit & Kesimpulan \\
\hline Orientasi Pasar & \multirow{2}{*}{$>0.70$} & 0.854 & Valid \\
\cline { 1 - 2 } Kreativitas Produk & & 0.876 & Valid \\
\hline Inovasi Produk & & 0.763 & Valid \\
\hline Keuanggulan kompetitif & & 0.793 & Valid \\
\hline
\end{tabular}

Sumber : Data Olahan 


\section{Penilaian Model Struktural (Inner Model)}

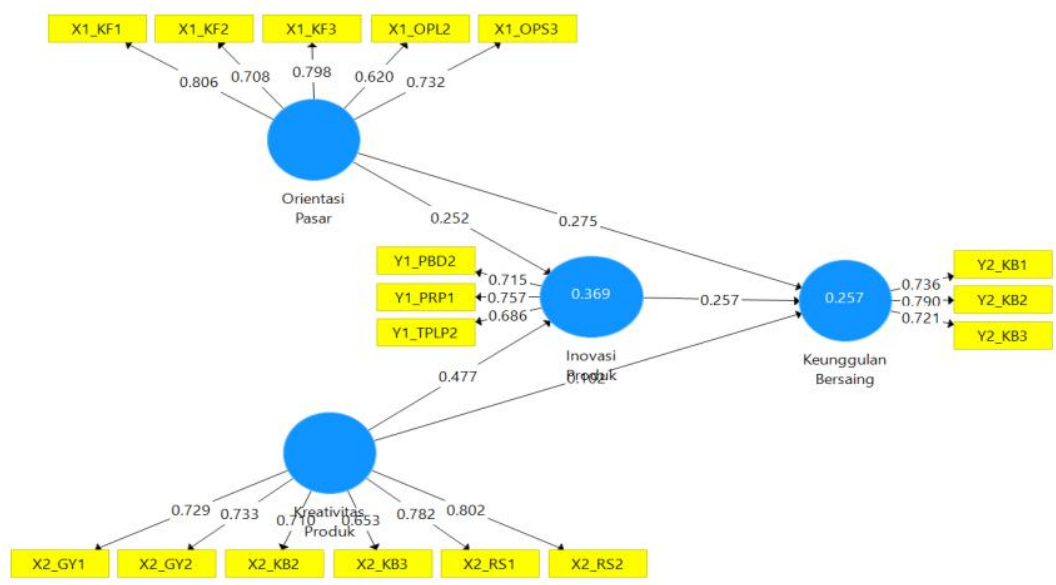

\section{Gambar 1 \\ Outer Loading dan Analisis Jalur}

R-square adalah uji model kesesuaian yang digunakan untuk menilai model struktural (Wiyono, 2020). Analisis data menunjukkan bahwa pengaruh orientasi pasar dan kreativitas produk terhadap inovasi produk adalah 0,369 (36,9\%); dan pengaruh orientasi pasar dan kreativitas produk terhadap keunggulan kompetitif adalah 0,257 $(25,7 \%)$ sedangkan sisanya dipengharui oleh variabel lain yang tidak di bahas pada penelitian ini. Seperti yang ditunjukkan pada Gambar. 1

\section{Uji Hipotesis}

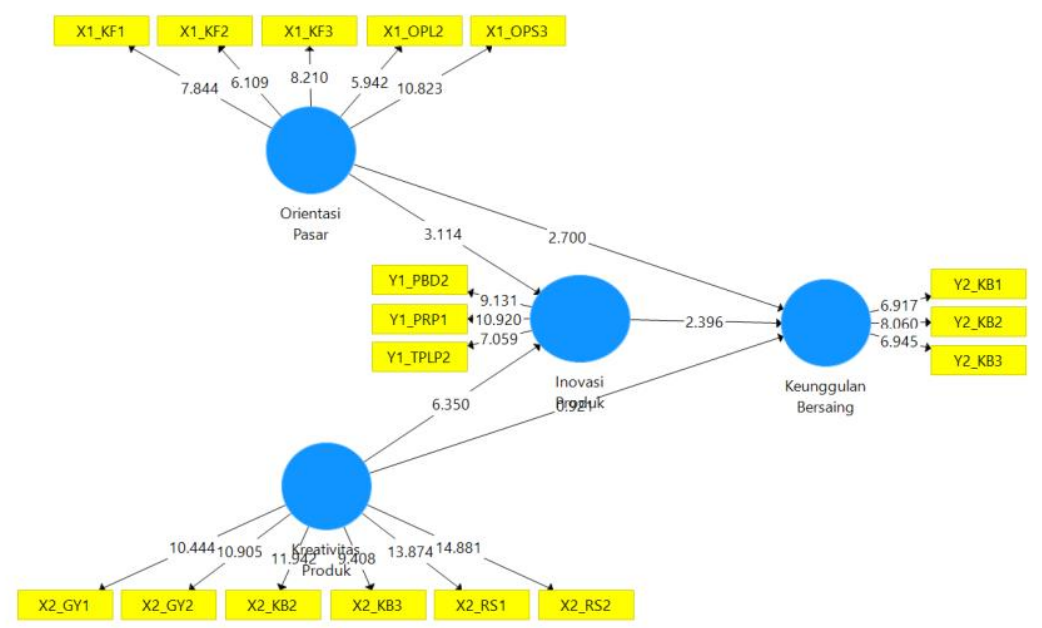

\section{Gambar 2}

Model Bootstrapping

Tabel 4

Hasil Uji Hipotesis

\begin{tabular}{|l|r|r|r|r|r|}
\hline & Original Somple & Sample Mean & Standard Deviation & $T_{\text {Statitics }}$ & $P$ Vaues \\
\hline Orientasi Pasar $\rightarrow$ Inovasi Produk & 0.252 & 0.264 & 0,081 & 3.102 & 0,002 \\
\hline Orientasi Pasar $\rightarrow$ Keunggulan kompetitif & 0.275 & 0.283 & 0.102 & 2.689 & 0.007 \\
\hline Kreativitas Produk $\rightarrow$ Inovasi Produk & 0.477 & 0.484 & 0.075 & 6.356 & 0,000 \\
\hline Kreativitas Produk $\rightarrow$ Keunggulan kompetitif & 0.102 & 0.104 & 0.111 & 0.922 & 0.357 \\
\hline Inovasi Produk $\rightarrow$ Keunggulan kompetitif & 0.257 & 0.263 & 0.109 & 2.363 & 0,018 \\
\hline
\end{tabular}

Sumber : Data Olahan

Hasil pengujian hipotesis pada tabel V. diatas, pengaruh antar variabel dapat dilihat dari nilai $\mathrm{t}_{\text {statistik }}$ dan $\mathrm{P}_{\text {Value }}$. Apabila nilai $\mathrm{P}_{\text {Value }}<0,05$ dan nilai $t_{\text {statistik }}$ menunjukan nilai diatas $t_{\text {tabel }}$ maka hipotesis tersebut terbukti berpengaruh, namun jika data menunjukan sebaliknya maka hipotesis tersebut tidak terbukti (Wiyono, 2020). Hal ini dapat dijelaskan sebagai berikut: Hasil pengujian hipotesis pertama menunjukan bahwa hubungan variabel orientasi pasar (X1) dengan inovasi produk (Y1) menunjukan nilai $\mathrm{t}_{\text {statistik }} 3.102(>1.96)$ dan $\mathrm{P}_{\text {Value }}$ sebesar $0.002(<0.05)$. Hal ini 
menunjukan bahwa variabel orientasi pasar terbukti berpengaruh positif dan signifikan terhadap variabel inovasi produk (Y1). Dengan demikian hipotesis 1 diterima. Hasil penelitian ini sesuai dengan hasil penelitian Sukaryawan (2013), Fadhilah and Andriyansah (2017); Wilches et al. (2018); Na, Kang and Jeong (2019); Sukartini et al. (2019); Shaher and Ali (2020) dan Aydin (2020) yang menunjukkan bahwa orientasi pasar berpengaruh positif dan signifikan terhadap terciptanya inovasi produk. Hasil pengujian hipotesis kedua menunjukan bahwa hubungan variabel orientasi pasar (X1) dengan keunggulan kompetitif (Y2) menunjukan nilai $t_{\text {statistik }} 2.689$ (>1.96) dan $\mathrm{P}_{\text {Value }}$ sebesar $0.007(<0.05)$. Hal ini menunjukan bahwa variabel orientasi pasar terbukti berpengaruh positif dan signifikan terhadap variabel keunggulan kompetitif (Y2). Dengan demikian hipotesis 2 diterima. Hal tersebut sejalan dengan temuan dari penelitian Talaja et al. (2017); Udriyah et al. (2019); Pratono et al. (2019); Kumbara and Afuan (2019) dan Puspaningrum (2020) yang mengungkapkan bahwa orientasi pasar berpengaruh signifikan terhadap terciptanya keunggulan kompetitif. Sebaliknya, tidak sejalan dengan hasil penelitian Zainul et al. (2016) yang mengungkapkan bahwa orientasi pasar tidak berpengaruh terhadap terciptanya keunggulan kompetitif. Hasil pengujian hipotesis ketiga menunjukan bahwa hubungan variabel kreativitas produk (X2) dengan inovasi produk (Y1) menunjukan nilai $\mathrm{t}_{\text {statistik }}$ $6.356(>1.96)$ dan $\mathrm{P}_{\text {Value }}$ sebesar $0.000(<0,05)$. Hal ini menunjukan bahwa variabel kreativitas produk terbukti berpengaruh positif dan signifikan terhadap variabel inovasi produk (Y1). Dengan demikian hipotesis 3 diterima. Hasil penelitian ini memperkuat hasil penelitian Sarooghi et al. (2015); Valaei et al. (2017); Anjaningrum and Sidi (2018); Ogbeibu et al. (2019) dan Ferreira et al. (2020) yang menunjukkan bahwa kreativitas produk berpengaruh signifikan terhadap lahirnya berbagai produk-produk dari hasil inovasi.

Hasil pengujian hipotesis keempat menunjukan bahwa hubungan variabel kreativitas produk (X2) dengan keunggulan kompetitif (Y2) menunjukan nilai $t_{\text {statistik }} 0.922(<1.96)$ dan $\mathrm{P}_{\text {Value }}$ sebesar $0.357(>0,05)$. Hal ini menunjukan bahwa variabel kreativitas produk berpengaruh positif tetapi tidak signifikan terhadap variabel keunggulan kompetitif (Y2). Dengan demikian hipotesis 4 ditolak. Hasil penelitian ini tidak sejalan dengan hasil penelitian Kosar et al. (2017); Bashor and Purnama (2017); Zameer et al. (2019); Noviani (2020) dan Yusuf et al. (2020) yang mengungkapkan bahwa kreativitas berpengaruh signifikan terhadap keunggulan kompetitif. Sebaliknya hasil penelitian ini sesuai dengan hasil penelitian dari Sutapa et al., 2017; dan Lee and Rodríguez-Pose, 2014 yang mengungkapkan bahwa kreativitas produk berpengaruh positif tetapi tidak signifikan terhadap keunggulan kompetitif. Hasil pengujian hipotesis kelima menunjukan bahwa hubungan variabel inovasi produk (Y1) dengan keunggulan kompetitif (Y2) menunjukan nilai $t_{\text {statistik }} 2.363(>1.96)$ dan $\mathrm{P}_{\text {Value }} 0,018(<0,05)$. Hal ini menunjukan bahwa variabel inovasi produk terbukti berpengaruh positif dan signifikan terhadap variabel keunggulan kompetitif (Y2). Dengan demikian hipotesis 5 diterima. Hasil penelitian ini sejalan dengan hasil penelitian dari Aziz and Samad (2016); Tarus et al. (2017); Nuryakin (2018); Kariuki (2017) dan Aktharsha and Prabhu (2019) yang menunjukkan bahwa inovasi produk berpengaruh signifikan terhadap tercapainya keunggulan kompetitif perusahaan.

\section{Analisis Mediasi}

Tabel 5

Analisis Mediasi Tes Sobel

\begin{tabular}{|l|l|l|l|}
\hline \multirow{2}{*}{\multicolumn{2}{|c|}{ Variabel }} & \multicolumn{3}{c|}{ Tes Sobel } \\
\cline { 2 - 4 } & \multicolumn{3}{c|}{ Keunggulan kompetitif (Y2) } \\
\cline { 2 - 4 } & Z score & P Value & Kesimpulan \\
\hline Orientasi Pasar (X1) & 1.873 & 0.061 & Mediasi tidak berperan \\
\hline Kreativitas Produk (X2) & 2.229 & 0.026 & Mediasi berperan \& Sig. \\
\hline
\end{tabular}

Sumber : Data Olahan

Kriteria pengujian tes sobel yaitu apabila $Z_{\text {score }}>Z_{\text {tabel }}$ maka membuktikan bahwa variabel mediasi mampu berperan menjadi mediator antara variabel independen dengan variabel dependen (Yay, 2017), atau Jika $P_{\text {value }} \leq 0,05$ dapat disimpulkan bahwa mediasi signifikan secara statistik (Dastgeer et al., 2020). Pada penelitian ini tes sobel dilakukan menggunakan program Microsoft Excel dari Moarefi and Sweis (2018). Berdasarkan analisis tes sobel pengaruh variabel orientasi pasar (X1) terhadap variabel keunggulan kompetitif (Y2) dimediasi oleh variabel inovasi produk (Y1) diperoleh nilai $Z_{\text {score }}$ sebesar $1.873<1.96$ dan $\mathrm{P}_{\text {value }}$ sebesar $0.061>0.05$. Hal ini berarti bahwa, variabel inovasi produk (Y1) tidak mampu berperan sebagai mediator pada pengaruh orientasi pasar (X1) terhadap keunggulan kompetitif (Y2). Berdasarkan hal tersebut dapat dimaknai bahwa pengaruh langsung dari variabel orientasi pasar terhadap keunggulan bersaing lebih tinggi dibandingkan pengaruhnya melalui inovasi produk. Berdasarkan analisis tes sobel pengaruh variabel kreativitas produk (X2) terhadap variabel keunggulan kompetitif (Y2) dimediasi oleh variabel inovasi produk (Y1) diperoleh nilai $\mathrm{Z}_{\text {score }}$ sebesar $2.229>1.96$ dan $\mathrm{P}_{\text {value }}$ sebesar $0.026<0.05$. Hal ini berarti bahwa, variabel inovasi produk (Y1) mampu berperan sebagai mediator secara signifikan pada pengaruh kreativitas produk (X2) terhadap keunggulan kompetitif (Y2). Berdasarkan hal tersebut dapat dimaknai bahwa pengaruh variabel 
kreativitas produk terhadap keunggulan kompetitif melaui inovasi produk lebih tinggi dibandingkan pengaruh langsungnya terhadap keunggulan kompetitif sehingga memiliki ide yang kreatif saja tentu dirasa belum cukup jika tidak diwujudkan menjadi sebuah produk nyata melalui inovasi produk yang mampu menciptakan keunggulan kompetitif.

\section{Simpulan}

Berdasarkan analisis dan pembahasan diatas, maka dapat disimpulkan bahwa orientasi pasar berpengaruh signifikan terhadap inovasi produk dan keunggulan kompetitif; kreativitas produk berpengaruh signiifikan terhadap inovasi produk tetapi tidak signifikan terhadap keunggulan kompetitif. Pada hasil analisis tes sobel menunjukkan bahwa inovasi produk mampu memediasi secara signifikan pengaruh kreativitas produk terhadap keunggulan kompetitif tetapi tidak mampu berperan sebagai mediator pada pengaruh orientasi pasar terhadap keunggulan kompetitif.

\section{Daftar Pustaka}

Aksoy, H. (2017). How do innovation culture, marketing innovation and product innovation affect the market performance of small and medium-sized enterprises (SMEs)? Technology in Society, 51, 133-141. https://doi.org/10.1016/j.techsoc.2017.08.005

Aktharsha, U. S., \& Prabhu, P. (2019). The Effect Of Innovation On Competitive Advantage In It Companies: An Empirical Investigation. A Journal Of Composition Theory, 12(9), 1013-1025.

Anjaningrum, W. D., \& Sidi, A. P. (2018). Pengaruh Orientasi Pasar, Inovasi Dan Kreativitas Produk Terhadap Kinerja Industri Kreatif Untuk Mencapai Keunggulan Bersaing. Jurnal Ilmiah Bisnis Dan Ekonomi Asia, 12(2), 30-47. https://doi.org/10.32812/jibeka.v12i2.22

Anwar, M., Rehman, A. U., \& Shah, S. Z. A. (2018). Networking and New Venture's Performance: Mediating Role of Competitive Advantage. International Journal of Emerging Markets. https://doi.org/10.1108/IJoEM-07-20170263

Assensoh-Kodua, A. (2019). The resource-based view: A tool of key competency for competitive advantage. Problems and Perspectives in Management, 17(3), 143-152. https://doi.org/10.21511/ppm.17(3).2019.12

Atalay, M., Anafarta, N., \& Sarvan, F. (2013). The Relationship between Innovation and Firm Performance: An Empirical Evidence from Turkish Automotive Supplier Industry. Procedia - Social and Behavioral Sciences, 75, 226-235. https://doi.org/10.1016/j.sbspro.2013.04.026

Ayandibu, A. O., \& Houghton, J. (2017). The role of Small and Medium Scale Enterprise in local economic development (LED). Banach Journal of Mathematical Analysis, 11(2), 133-139.

Aydin, H. (2020). Market orientation and product innovation: the mediating role of technological capability. European Journal of Innovation Management, 10(6). https://doi.org/10.1108/EJIM-10-2019-0274

Aziz, N. N. A., \& Samad, S. (2016). Innovation and Competitive Advantage: Moderating Effects of Firm Age in Foods Manufacturing SMEs in Malaysia. Procedia Economics and Finance, 35(10), 256-266. https://doi.org/10.1016/s2212-5671(16)00032-0

Bantul, P. K. (2019). Laporan Kinerja (LKj) Pemerintah Kabupaten Bantul.

Bashor, C., \& Purnama, C. (2017). Factors Affecting Performance Manager and Its Impact on Competitive Advantage: Studies Small Medium Enterprises (SMEs) in The Shoes Industry Mojokerto East Java Province. Mediterranean Journal of Social Sciences, 8(4), 153-162. https://doi.org/10.1515/mjss-2017-0014

Bruno, F. da S., Netto, H. F., \& Bruno, A. C. M. (2011). Aspects That Boost Innovative Potential Of Textile And Apparel Industry In Flanders District Of Creativity: Inspirations For The Design Of Policies In Brazil. Revista Produção Online, 11(4), 1028-1058. https://doi.org/https://doi.org/10.14488/1676-1901.v11i4.713

Carboni, O. A., \& Russu, P. (2018). Complementarity in product, process, and organizational innovation decisions: evidence from European firms. $R$ and D Management, 48(2), 210-222. https://doi.org/10.1111/radm.12284

Chang, D., \& Chen, C.-H. (2014). Understanding the influence of customers on product innovation. International Journal of Agile Systems and Management, 7(3-4), 348-364. https://doi.org/10.1504/IJASM.2014.065350

Dastgeer, G., Rehman, A. ur, \& Asghar, M. A. (2020). Selection and use of mediation testing methods ; application in management sciences. Business \& Economic Review, 12(3), 1-48. https://doi.org/10.22547/BER/12.3.1

Ernawati, S., \& Kurniawati, U. (2020). Pengaruh Kreatifitas Produk Dan Inovasi Produk Terhadap Kepuasan Konsumen Di Steak House Noodles. ISOQUANT : Jurnal Ekonomi, Manajemen Dan Akuntansi, 4(1), 112 119. https://doi.org/10.24269/iso.v4i1.399

Fadhilah, M., \& Andriyansah. (2017). Strategic implementation of environmentally friendly innovation of small and medium-sized enterprises in Indonesia. European Research Studies Journal, 20(4), 134-148. https://doi.org/10.35808/ersj/880

Fazlagić, J., \& Skikiewicz, R. (2019). Measuring sustainable development - the creative economy perspective. 
Andika et al., Membangun Keunggulan Kompetitif Melalui Orientasi Pasar, Kreativitas Produk dan Inovasi Produk Pada IKM Kerajinan Kabupaten Bantul Yogyakarta

International Journal of Sustainable Development and World Ecology, 26(7), 635-645. https://doi.org/10.1080/13504509.2019.1651418

Ferreira, J., Coelho, A., \& Moutinho, L. (2020). Dynamic capabilities, creativity and innovation capability and their impact on competitive advantage and firm performance: The moderating role of entrepreneurial orientation. Technovation, 92-93(November). https://doi.org/10.1016/j.technovation.2018.11.004

Ghorbani, H., Dalvi, M. R., \& Hirmanpour, I. (2014). Studying the Effect of Market Orientation on Marketing Effectiveness Case Study: Hotels in Isfahan province. International Journal of Academic Research in Business and Social Sciences, 4(1), 570-579. https://doi.org/10.6007/IJARBSS/v4-i1/563

Hadiyati, E. (2011). Kreativitas dan Inovasi Berpengaruh Terhadap Kewirausahaan Usaha Kecil. Jurnal Manajemen Dan Kewirausahaan, 13(1). https://doi.org/10.9744/jmk.13.1.8-16

Hair, J. F., Hollingsworth, C. L., Randolph, A. B., \& Chong, A. Y. L. (2017). An Updated and Expanded Assessment of PLS-SEM in Information Systems Research Introduction. Industrial Management \& Data Systems, 117(3), 1-41. https://doi.org/http://dx.doi.org/10.1108/IMDS-04-2016-0130

Hair, Joseph F, Hult, G. T. M., Ringle, C. M., \& Sarstedt, M. (2017). A Primer on Partial Least Squares Structural Equation Modeling (PLS-SEM). In Asia-Pacific Pte. Ltd (Second). SAGE Publications, Inc.

Im, S., Montoya, M. M., \& Workman, J. P. (2013). Antecedents and consequences of creativity in product innovation teams. Journal of Product Innovation Management, 30(1), 170-185. https://doi.org/10.1111/j.15405885.2012.00887.x

Kariuki, A. N. (2017). Effects Of Innovation Strategy In Enhancing Competitive Advantage Among Commercial Banks In Kenya [United States International University-Africa]. https://doi.org/10.37513/ciar.v10i2.495

Kosar, S. T., Machova, R., \& Simonova, M. (2017). Creativity in practice in the context of applied management methods and tools. Marketing and Management of Innovations, 2, 182-195. https://doi.org/10.21272/mmi.2017.2-17

Kumar, V., Jones, E., Venkatesan, R., \& Leone, R. P. (2011). Is Market Orientation a Source of Sustainable Competitive Advantage or Simply the Cost of Competing? Journal of Marketing, 75(1), 16-30. https://doi.org/10.1509/jm.75.1.16

Kumbara, V. B., \& Afuan, M. (2019). The Influence of Product Innovation and Market Orientation on the Competitive Advantages of Bengkuang Processed Products in Padang. International Journal of Latest Engineering and Management Research (IJLEMR), 04(09), 31-38. www.ijlemr.com

Kumlu, O. (2014). The Effect of Intangible Resources and Competitive Strategies on the Export Performance of Small and Medium Sized Enterprises. Procedia - Social and Behavioral Sciences, 150, 24-34. https://doi.org/10.1016/j.sbspro.2014.09.004

Kurniasari, R. ., \& Utama, A. (2018). the Effect of Product Innovation, Product Creativity, and Product Quality on Competitive Advantage (a Case Study of Handicraft Enceng Gondok “Akar"). Manajemen Dan Bisnis Indonesia, 3, 467-477. http://okezone.com

Ladipo, P. K. A., Rahim, A. G., Oguntoyibo, C. A., \& Okikiola, I. O. (2016). Market Orientation and Business Performance a Study of Interrelationships and Effects in a Small sized Hotels within Lagos State Metropolis. Academic Journal of Economic Sudies, 2(4), 98-119.

Lee, N., \& Rodríguez-Pose, A. (2014). Innovation in Creative Cities: Evidence from British Small Firms. Industry and Innovation, 21(6), 494-512. https://doi.org/10.1080/13662716.2014.983748

Mamun, A. Al, Mohiuddin, M., Fazal, S. A., \& Ahmad, G. Bin. (2018). Effect of entrepreneurial and market orientation on consumer engagement and performance of manufacturing SMEs. Management Research Review, 41(1), 133-147. https://doi.org/10.1108/MRR-04-2017-0102

Marinho, E. da S., González, M. O. A., Galvão, M. S., Araújo, A. C. C. de, Rosa, M. S. C., \& Pereira, J. R. (2016). Relationship between creativity and product innovation: A literature review. Product Management \& Development, 14(1), 32-37. https://doi.org/10.4322/pmd.2016.007

Moarefi, A., \& Sweis, R. J. (2018). Sobel Test. https://www.researchgate.net/publication/329371676_Sobel_test

Muharam, D. R. (2017). Penerapan Konsep Resources-Based View (Rbv) Dalam Upaya Mempertahankan Keunggulan Bersaing Perusahaan. Jurnal Ilmu Administrasi: Media Pengembangan Ilmu Dan Praktek Administrasi, 14(1), 82-95. https://doi.org/10.31113/jia.v14i1.4

Na, Y. K., Kang, S., \& Jeong, H. Y. (2019). The Effect of Market Orientation on Performance of Sharing Economy Business : Focusing on Marketing Innovation and Sustainable Competitive Advantage. Sustainability Article, 11,1-19. https://doi.org/10.3390/su11030729

Noviani, L. (2020). Pengaruh Inovasi Produk, Kreativitas Produk, Dan Kualitas Produk Terhadap Keunggulan Bersaing (Studi Kasus Pada Kerajinan Tikar Eceng Gondok" Liar”. Jurnal Manajemen Dan Bisnis, 2(01), 2076-2086. https://doi.org/: 10.47080

Nuryakin. (2018). Competitive advantage and product innovation: Key success of Batik SMEs marketing performance 
Andika et al., Membangun Keunggulan Kompetitif Melalui Orientasi Pasar, Kreativitas Produk dan Inovasi Produk Pada IKM Kerajinan Kabupaten Bantul Yogyakarta

in Indonesia. Academy of Strategic Management Journal, 17(2), 1-17.

Odumeru, J. A. (2013). Innovation and Organisational Performance. Kuwait Chapter of Arabian Journal of Business and Management Review, 2(12), 18-22. https://doi.org/10.12816/0001266

Ogbeibu, S., Emelifeonwu, J., Senadjki, A., Gaskin, J., \& Kaivo-oja, J. (2019). Technological turbulence and greening of team creativity, product innovation, and human resource management: Implications for sustainability. Journal of Cleaner Production, 1-49. https://doi.org/10.1016/j.jclepro.2019.118703

Petry, J. F., Uchoa, A. G. F., Mendonça, M. B. de, Magalhaes, K. de L., \& Benchimol, R. M. B. (2020). The creative economy: an ethnographic framework for handcrafts in the Alto Solim oes region of the Brazilian Amazon. International Journal of Social Economics. https://doi.org/10.1108/IJSE-04-2020-0262

Piffer, D. (2012). Can creativity be measured? An attempt to clarify the notion of creativity and general directions for future research. Thinking Skills and Creativity, 7(3), 258-264. https://doi.org/10.1016/j.tsc.2012.04.009

Pratono, A. H., Darmasetiawan, N. K., Yudiarso, A., \& Jeong, B. G. (2019). Achieving sustainable competitive advantage through green entrepreneurial orientation and market orientation: The role of inter-organizational learning. Bottom Line, 32(1), 2-15. https://doi.org/10.1108/BL-10-2018-0045

Puspaningrum, A. (2020). Market Orientation, Competitive Advantage and Marketing Performance of Small Medium Enterprises (SMEs). Journal of Economics, Business, \& Accountancy Ventura, 23(1), 19. https://doi.org/10.14414/jebav.v23i1.1847

Putra, I. G. D., \& Rahanatha, G. B. (2017). Peran Inovasi Produk Memediasi Orientasi Pasar Terhadap Kinerja Pemasaran. 6(8), 4361-4390.

Raju, P. S., Lonial, S. C., \& Crum, M. D. (2011). Market orientation in the context of SMEs: A conceptual framework. Journal of Business Research, 64(12), 1320-1326. https://doi.org/10.1016/j.jbusres.2010.12.002

Reguia, C. (2014). Product Innovation and the Competitive Advantage. European Scientific Journal, I(June), 140157.

Rifa'i, M., Sasongko, T., \& Indrihastuti, P. (2019). Meningkatkan Keunggulan Bersaing Produk Melalui Inovasi Dan Orientasi Pasar Pada Usaha Sektor Industri Kreatif Di Kota Malang. J u r n a l E K B I S, 20(1), 1194-1205.

Roach, D. C., Ryman, J., \& White, J. (2014). Culture, Conduct And Innovation: A Deconstruction Of Market Orientation. Journal of Research in Marketing and Entrepreneurship, 16(2). http://dx.doi.org/10.1108/JRME01-2014-0002

Romli, M. E. (2019). Kreativitas dan Inovasi Dalam Pemasaran Untuk Mempertahankan dan Mengembangkan Kinerja Merek. Jurnal Media Wahana Ekonomika, 16(3), 218. https://doi.org/10.31851/jmwe.v16i3.3422

Ruzikna. (2018). Implementasi kreativitas bisnis dan pengaruhnya terhadap keunggulan bersaing. Jurnal Aplikasi Bisnis, 8(2), 89-94.

Salerno, M. S., Gomes, L. A. D. V., Da Silva, D. O., Bagno, R. B., \& Freitas, S. L. T. U. (2015). Innovation processes: Which process for which project? Technovation, 35, 59-70. https://doi.org/10.1016/j.technovation.2014.07.012

Sarooghi, H., Libaers, D., \& Burkemper, A. (2015). Examining the relationship between creativity and innovation: A meta-analysis of organizational, cultural, and environmental factors. Journal of Business Venturing, 30(5), 714-731. https://doi.org/10.1016/j.jbusvent.2014.12.003

Shaher, A. T. H. Q., \& Ali, K. A. M. (2020). The effect of entrepreneurial orientation and knowledge management on innovation performance: The mediation role of market orientation. Management Science Letters, 10(15), 3723-3734. https://doi.org/10.5267/j.msl.2020.6.020

Sombultawee, K., \& Boon-itt, S. (2018). Marketing-operations alignment: A review of the literature and theoretical background. Operations Research Perspectives, 5, 1-12. https://doi.org/10.1016/j.orp.2017.11.001

Streimikiene, D., \& Kac erauskas, T. (2020). The creative economy and sustainable development: The Baltic States. ERP Environment and John Wiley \& Sons Ltd, 7, 1-10. https://doi.org/10.1002/sd.2111

Suhaeni, T. (2018). Pengaruh Strategi Inovasi Terhadap Keunggulan Bersaing di Industri Kreatif (Studi Kasus UMKM Bidang Kerajinan Tangan di Kota Bandung). Jurnal Riset Bisnis Dan Investasi, 4(1), 57. https://doi.org/10.35697/jrbi.v4i1.992

Sukartini, N. W., Kencanawati, A. A. A. M., \& Lasmini, N. K. (2019). Market Orientation and Its Impact on Product Innovation and Marketing Performance of SMEs in Bali. Advances in Social Science, Education and Humanities Research, 383, 218-221. https://doi.org/10.2991/icss-19.2019.18

Sukaryawan, I. M. (2013). Pengaruh Orientasi Pasar, Kewirausahaan, Dan Inovasi Terhadap Kinerja Bisnis Pada Perusahaan Aspal-Beton (Hotmix) Di Jabodetabek. Jurnal MIX, 3(2), 231-246. https://doi.org/10.22441/jurnal_mix

Sutapa, Mulyana, \& Wasitowati. (2017). The Role of Market Orientation, Creativity and Innovation in Creating Competitive Advantages and Creative Industry Performance. Jurnal Dinamika Manajemen, 8(2), 152-166. https://doi.org/http://dx.doi.org/10.15294/jdm.v8i2.12756 
Symons, J., \& Hurley, U. (2018). Strategies for connecting low income communities to the creative economy through play: two case studies in Northern England. Creative Industries Journal, 11(2), 121-136. https://doi.org/10.1080/17510694.2018.1453770

Talaja, A., Miočević, D., Alfirević, N., \& Pavičić, J. (2017). Market Orientation, Competitive Advantage and Business Performance: Exploring the Indirect Effects. Drustvena Istrazivanja, 26(4). https://doi.org/10.5559/di.26.4.07

Tarus, V., Boit, R., \& Korir, M. (2017). Incremental Innovation And Firm's Competitive Advantage: A Quantitative Analysis Approach. International Journal of Quantitative and Qualitative Research Methods, 5(1), 22-30. www.eajournals.org

Tremblay, G. (2011). Criatividade e pensamento crítico. Intercom: Revista Brasileira de Ciências Da Comunicação, 34(1), 255-266. https://doi.org/10.1590/s1809-58442011000100013

Udriyah, Tham, J., \& Ferdous Azam, S. M. (2019). The effects of market orientation and innovation on competitive advantage and business performance of textile smes. Management Science Letters, 9(9), 1419-1428. https://doi.org/10.5267/j.msl.2019.5.009

Valaei, N., Rezaei, S., \& Ismail, W. K. W. (2017). Examining learning strategies, creativity, and innovation at SMEs using fuzzy set Qualitative Comparative Analysis and PLS path modeling. Journal of Business Research, 70, 224-233. https://doi.org/10.1016/j.jbusres.2016.08.016

Wang, H.-L. (2014). Theories for competitive advantage. Being Practical with Theory: A Window into Business Research, January 2014, 33-43.

Wilches, A. C. O., Valencia, J. C. N., \& Jimenez, D. J. (2018). Market orientation and innovation: Do structure and environment moderate this relationship? Espacios, 39(42).

Wiyono, G. (2020). Merancang Penelitian Bisnis Dengan Alat Analisis SPSS 25 \& SmartPLS 3.2.8 (Kedua). UPP STIM YKPN.

Yay, M. (2017). the Mediation Analysis With the Sobel Test and the Percentile Bootstrap. International Journal of Management and Applied Science, 3(2), 978-993.

Yuniarti, S., Imron, A., Sanusi, A., \& Chandrarin, G. (2018). An empirical study on income equality, economic growth and financial inclusion in Indonesia: model development on SMEs financing. International Journal of Education Economics and Development, 9(4), 346. https://doi.org/10.1504/ijeed.2018.10017282

Yusuf, R., Veranita, M., Hendrayati, H., \& Nur, N. (2020). The Influence Of Creativity And Innovation On Competitive Excellence On Cv . Tory Catering Bandung (Smes). Proceeding of IICSDGs, 3(1), 28-33.

Zainul, M., Astuti, ndang S., Arifin, Z., \& Utami, H. N. (2016). The Effect of Market Orientation toward Organizational Learning, Innovation, Competitive Advantage, and Corporate Performance. Journal of Administrative Sciences and Policy Studies, 4(1), 1-19. https://doi.org/10.15640/jasps.v4n1a1

Zaman Khan, S., Waheed, A., Arshad, S., Rafique, K., \& Laeeq, M. (2016). How Market Orientation Helps to Gain Competitive Advantages in New Product Offering (Comparative Analysis between Market Oriented \& NonMarket Oriented Firms). International Journal of Advances in Management, Economics and Entrepreneurship, 3(3), 1-7. www.ijamee.info

Zameer, H., Wang, Y., \& Yasmeen, H. (2019). Reinforcing green competitive advantage through green production, creativity and green brand image: Implications for cleaner production in China. Journal of Cleaner Production, 247. https://doi.org/10.1016/j.jclepro.2019.119119

Zizlavsky, O. (2011). Involving customers in the innovation process as a means of increasing business performance. Journal of Competitiveness, 3(1), 15-24. 